\title{
Eco-friendly dyeing of wool and pashmina fabric using Quercus robur L. (fruit cups) dye and Salix alba L. (wood extract) mordant
}

\author{
Syed Maqbool Geelani ${ }^{*}$, Shoukat Ara ${ }^{1}$, Pradeep Kumar Mishra ${ }^{2}$, S.J.A. Bhat ${ }^{3}$, Syed Hanifa ${ }^{4}$, \\ Shamsul Haq ${ }^{1}$, Iqbal Jeelani ${ }^{5}$, Gazala Qazi ${ }^{1}$, Asif H Sofi ${ }^{6}$, Shakeel A Mir ${ }^{5}$, P.A. Khan ${ }^{3}$, Sarfaraz \\ A Wani ${ }^{6}$ and A S.M. Raja ${ }^{7}$ \\ ${ }^{1}$ Division of Environmental Sciences, Sher-e-Kashmir University of Agricultural Sciences and Technology of \\ Kashmir, Shalimar-190025 (J\&K), INDIA. \\ ${ }^{2}$ Department of Chemical Engineering \& Technology, Indian Institute of Technology (Banaras Hindu University), \\ Varanasi-221005.(UP), INDIA \\ ${ }^{3}$ Faculty of Forestry, Sher-e-Kashmir University of Agricultural Sciences and Technology of Kashmir, Wadura-193201, \\ (J\&K), INDIA \\ ${ }^{4}$ Department of Food Sciences \& Technology, University of Kashmir, Hazratbal, Srinagar-190006 (J\&K), INDIA \\ ${ }^{5}$ Division of Agricultural Statistics, Sher-e-Kashmir University of Agricultural Sciences and Technology of Kashmir, \\ Shalimar-190025 (J\&K), INDIA \\ ${ }^{6}$ Division of Livestock Products Technology, Faculty of Veterinary Science \& Animal Husbandry, Sher-e-Kashmir \\ University of Agricultural Sciences and Technology of Kashmir, Shuhama-190006 (J\&K), INDIA \\ ${ }^{7}$ Division of Textile Manufacture and Textile chemistry, Central Sheep and wool Research Institute, Avikanagar \\ - 304501 (Rajasthan), INDIA \\ *Corresponding author. E-mail: geelani111@gmail.com
}

Received: November 24, 2014; Revised received: February 20, 2015; Accepted: March 19, 2015

Abstract: Study was conducted to investigate the dyeing potential of Quercus robur L. (fruit cups) dye and Salix alba L. (wood extract) mordant on wool and pashmina fabrics. The experiment was conducted keeping in view the environmental safety by using unutilized plant materials and excluding the usage of chemical agents. The dyeing was carried out individually including and excluding mordant adopting different mordanting methods. The parameters like percent absorption, colour coordinates, colour strength $(\mathrm{K} / \mathrm{S})$, relative colour strength and colour fastness with regard to washing, light and rubbing were investigated. The results revealed higher percent absorption of mordanted samples than unmordanted samples. Colour coordinates ( $\mathrm{L}^{*} \mathrm{a}^{*} \mathrm{~b}^{*}$, Chroma, hue and $\Delta \mathrm{E}$ ) of dyed wool and pashmina fabric exhibited satisfactory results. The colour strength $(\mathrm{K} / \mathrm{S})$ and relative colour strength of pashmina fabric recorded higher than wool fabric. The fastness properties to washing, light and rubbing showed satisfactory grades including and excluding natural mordant. However, the grades of mordanted samples were found better than unmordanted samples. The dye and mordant in isolation and in combination showed beautiful colours and shades on selected fabrics with satisfactory retention properties, hence can be utilized commercially for coloration of wool and pashmina fabrics.

Keywords: Dyeing, Pashmina, Quercus robur, Salix alba, Wool

\section{INTRODUCTION}

The importance of colour in textiles has been recognized before thousands of years (Vankar, 2000). There are a vast number of natural colours that can be obtained from nature. Leaves, roots, flowers, barks, fruits and stems can be explored as potential dyeing sources for different fabrics. The natural dyes are clinically safer than their synthetic analogues, in handling and use because of non-carcinogenic and biodegradable nature (Aminoddin and Haji, 2010). Natural dyes have gained importance due to the growing environmental awareness and implementation of stringent regulations on production and use of synthetic dyes (Arun and Yogamoorthi,
2014). Synthetic dyes are designed to resist chemicals, and improve the quality of the product but are persistent in the environment. The chemicals used to produce synthetic dyes are highly toxic, carcinogenic, allergic, explosive and dangerous to work with. The production of synthetic dyes involves many violent reactions, which are considered health hazardous (Wilkinson and Mcgechan, 1996). The wastewater from textile plants is classified as the most polluting of all the industrial sectors, considering the volume generated as well as the effluent composition (Ben et al., 2012). The ingestion of water contaminated with textile dyes can cause serious damage to the human health and of other living organisms, due to the toxicity and mutagenicity of its components 
(Prado et al., 2004). The discharge of highly coloured synthetic dye effluents into inland and coastal waters is an environmental problem of growing concern (Padmavathy et al., 2003). Due to the carcinogenic effects, toxicity and allergic reactions associated with synthetic dyes interest in the revival of natural dyes in textile coloration is increasing (Kulkarni et al., 2011). Natural dyes exhibit better biodegradability and generally have a better compatibility with the environment. They are less toxic, polluting, health hazardous, non-carcinogenic, easily available and renewable (Adeel et al., 2009). Though possess lower toxicity and allergic reactions than synthetic dyes however, safety of natural dyes needs to be proved if they are used more widely and in commercial process (Kumar and Bharti, 1998). Considerable research work is being conducted throughout the world to search out new cheaper dye sources and extraction methods for producing sufficient quantities of viable safe natural pigments and dyes. Kashmir valley abounds in rich plant biodiversity with a rich potential of natural dyes and mordants which needs to get explored so as to replace the synthetic coloring agents. Quercus robur $\mathrm{L}$. is a deciduous tree with hard fruit nut bearing cups, which falls at ground at the time of ripening of fruit, which was utilized as dye source and Salix alba L. is a large tree with strong and branched trunk found abundantly in the valley of Kashmir mostly at moist places. The extracted materials were utilized as potential dyeing agents for wool and pashmina, which are mostly found in the valley and has worldwide significance, thus selected for dyeing. To protect the biodiversity of the plants, unutilized plant parts were selected as a source of dyeing agents.

\section{MATERIALS AND METHODS}

The plant material for dye extraction was collected from nursery of the Faculty of Forestry at university campus and material for mordant extraction was collected from university outskirts. Pashmina and wool were purchased from FS Shawls, Srinagar and Poshish (Jammu and Kashmir Handloom Development Corporation) outlet at Srinagar (J\&K), India.

Preparation of dyeing material: The shade dried fruit cups were washed with water to remove dirt and other adhering materials and then dried in tray drier at $80^{\circ} \mathrm{C}$ for 2 hours and finely powdered with the help of a grinding machine. The material was then passed through a standard test sieve No. 14.

Preparation of mordant: To prepare the mordant solution, the stem of willow (Salix alba L.) was cut into small pieces and soaked in distilled water for 30 days. 10 litres of distilled water was used for $1 \mathrm{Kg}$ of Willow stem wood. The solution was filtered and kept under refrigeration for future usage (Ferda et al., 2010).

Extraction of dye: Extraction of dye was performed by Soxhlet apparatus using distilled water as solvent. 1 litre of distilled water was used for $100 \mathrm{~g}$ plant material.
The material was kept for reflux for about $8 \mathrm{hrs}$. at $80-85^{\circ} \mathrm{C}$. The liquid extract was evaporated at $65^{\circ} \mathrm{C}$ in a rotary vacuum evaporator to one fourth of its original volume to get the final extract for dyeing.

Scouring of fabrics: Wool and Pashmina fabrics were washed with $2 \%$ non-ionic soap (Labolene) at $50^{\circ} \mathrm{C}$ for 20 min., maintaining the material-to-liquor ratio at 1:50. The scoured material was thoroughly washed with plenty of tap water and dried at room temperature. The scoured material was soaked in distilled water for 30 minutes prior to dyeing. All the fabrics were cut and sized into $5 \times 6 \mathrm{~cm}$ and used for dyeing experiments (Tiwari et al., 2010).

Dyeing of fabrics: Dyeing was carried out in a water bath, keeping material to liquor ratio 1:50. The scoured and washed fabrics were introduced in $250 \mathrm{ml}$ beaker containing $100 \mathrm{ml}$ of dye solution and $4 \%$ dye (OWM) at room temperature. The temperature was increased to $85-90{ }^{\circ} \mathrm{C}$ with gentle stirring. The process of dyeing was continued for 1 hour. The material was then removed and washed 2-3 times with $1 \%$ of detergent and water. The dyed samples were squeezed and dried at room temperature. The dyeing of the fabrics was done at acidic $\mathrm{pH}$ by adding acetic acid $\left(\mathrm{CH}_{3} \mathrm{COOH}\right)$.

Mordanting: Mordanting was carried out using 15\% of mordant and the process of mordanting was performed by following pre-mordanting, simultaneous mordanting and post-mordanting methods. The mordant was employed at Material to Liquor ratio of 1:50 and the process of mordanting was continued for 1 hour at $60-75^{\circ} \mathrm{C}$ of temperature.

Determination of percent absorption of dye: The percent absorption of the natural dye by the selected fabrics was carried out by recording the optical density of the dye solution both before and after dyeing. The ultraviolet-visible adsorption spectra (UV-VIS) was recorded on PC based double beam spectrophotometer (Systronics-2202) over the range of 200-800 nm. The percent absorption of natural dye was calculated by using the following equation (Divya et al., 2013).

Percent absorption $=\frac{0 . \mathrm{D} \text { before dyeing }-\mathrm{O} . \mathrm{D} \text { after dyeing }}{0 . \mathrm{D} \text { before dyeing }} \times 100$

Evaluation of CIE $L * a * b * C * \& h^{0}$ values of dyed fabrics: CIE $\mathrm{L}^{*} \mathrm{a} * \mathrm{~b}^{*}$ values of dyed and undyed fabrics were determined by Chromometer (Model CR-2000, Minolta, Osaka, Japan) equipped with $8 \mathrm{~mm}$ measuring head and AC illumination (6774 K) based on CIE system (International Commission on Illumination). The meter was calibrated using the manufacturer's standard white plate.

From the $\mathrm{L}^{*}, \mathrm{a}^{*}$ and $\mathrm{b}^{*}$ coordinates, Chroma $\left(\mathrm{C}^{*}\right)$ and hue angle $\left(\mathrm{h}^{\mathrm{o}}\right)$ values were calculated by the following equations (Aung and Win, 2008; Vankar and Rakhi, 2008; Atayde et al., 2011).

Chroma $=\left(a^{* 2}+b^{* 2}\right)^{1 / 2}$

Hue $=\left(\mathrm{h}=\tan ^{-1} \mathrm{~b}^{*} / \mathrm{a}^{*}\right)$

The total colour change of the dyed fabrics was calculated from the $\mathrm{L}^{*}, \mathrm{a}^{*}$ and $\mathrm{b}^{*}$ coordinates by applying the 
following equation.

Total colour change $(\Delta \mathrm{E})$ :

$(\Delta \mathrm{E})=\left[\left(\Delta \mathrm{L}^{*}\right)^{2}+\left(\Delta \mathrm{a}^{*}\right)^{2}+\left(\Delta \mathrm{b}^{*}\right)^{2}\right]^{1 / 2}$

Where,

$\Delta \mathrm{L} *=\mathrm{L} *$ sample $-\mathrm{L}^{*}$ standard

$\Delta \mathrm{a}^{*}=\mathrm{a}^{*}$ sample - $\mathrm{a}^{*}$ standard

$\Delta \mathrm{b} *=\mathrm{b} *$ sample $-\mathrm{b} *$ standard

Determination of surface colour strength (K/S) value: The colour strength $(\mathrm{K} / \mathrm{S})$ value of the undyed and dyed fabric samples was evaluated using a JAYPAK -4802 colour matching system (Jay Instruments Ltd., Mumbai, India) at D65 illuminate/10 Deg observer, (Jothi, 2008). The reflectance of the samples was measured at $360-760 \mathrm{~nm}$. The $\mathrm{K} / \mathrm{S}$ value in the visible region of the spectrum $(400-700 \mathrm{~nm})$ was calculated based on the Kubelka-Munk equation mentioned below.

$\frac{\mathrm{K}}{\mathrm{S}}=\frac{(1-\mathrm{R}:) 2}{2 \times \mathrm{R}:}$

Where, $\mathrm{K}$ is the coefficient of absorption, $\mathrm{S}$ is the scattering coefficient and $\mathrm{R}$ is the surface reflectance value of the sample at a particular wavelength, where maximum absorption occurs for a particular dye/colour component.

Relative colour strength: The Relative colour strength (K/S values at maximum wavelength) was determined using the following equation adopted by, Goodarzian and Ekrami (2010).

Relative Colour Strength $=\frac{(\mathrm{K} / \mathrm{S}) \text { Extracted }}{(\mathrm{K} / \mathrm{S}) \text { Raw }}$

Evaluation of colour fastness properties: The colour fastness tests for light, rubbing and washing were carried out as per ISO 105-B02, ISO 105 X-12 and ISO 105-C01. The grading for colour change and colour staining were evaluated as per ISO 105-AO2 and ISO 105-A03.

\section{RESULTS AND DISCUSSION}

Percent absorption of natural dye and mordant by selected fabrics: Mordant plays an important role with natural dyes by fixing dye into the fabric. The use of natural mordant has a great significance in enhancing the absorption of natural dye. As depicted in Fig. 1, mordanted samples recorded better percent absorption of dye than without mordanted samples. In pashmina fabric highest percent absorption was recorded adopting simultaneous-mordanting method followed by pre-mordanting, while as without mordant and post-mordanting recorded lowest absorption in pashmina fabric. In wool fabric pre-mordanting method recorded highest absorption of natural dye followed by simultaneous-mordanting and post-mordanting. However, without mordant sample recorded lowest value of percent absorption in wool fabric. The increase in percent absorption of dye in mordanted samples may be attributed to the formation of the chemical bridge between the dye and fabric through natural mordant, which get fixed on the fibre and helps in fixation of natural dye (Prabhu and Bhute, 2012). The Pashmina wool protein $\left(-\mathrm{NH}_{2}-\mathrm{OH}-\mathrm{COOH}\right)$ provides a bridge between the dye and the pashmina wool resulting in increase of percent absorption than the other fabrics (Temani et al., 2011), hence satisfactory results of the percent absorption was recorded even by using less percentage of the dye and mordant.

Colour coordinates and colour strength $(K / S)$ of selected dyed fabrics: As depicted in table 1 . All the dyed fabrics showed variation in $\mathrm{L}^{*}, \mathrm{a}^{*}, \mathrm{~b}^{*}, \mathrm{C}^{*}, \mathrm{~h}^{\mathrm{o}}$, $\Delta \mathrm{E}, \mathrm{K} / \mathrm{S}$ and relative $\mathrm{K} / \mathrm{S}$ values. Where, the lowest value of lightness $\left(\mathrm{L}^{*}\right)$ was recorded in without mordant pashmina fabric and the highest value of lightness $\left(\mathrm{L}^{*}\right)$ was recorded in without mordant wool fabric. Values of $\mathrm{L}^{*}$ of pashmina fabric recorded lower than the values of wool fabric indicating the darker shades of pashmina fabric than the wool fabric. In wool fabric the lowest lightness $\left(\mathrm{L}^{*}\right)$ value was recorded adopting post-mordanting method followed by simultaneous, pre and without mordant dyed samples. Lightness $\left(\mathrm{L}^{*}\right)$ of pashmina fabric recorded lowest in without mordant dyed sample followed by simultaneous, post-mordanting and pre-mordanting method. Values of $a^{*}$ and $b^{*}$ recorded positive in both wool and pashmina fabric where values of $b^{*}$ recorded higher than the values of $a^{*}$. The positive and higher values of $a^{*}$ and $b^{*}$ indicate much yellowish shades than reddish. In wool fabric value of Chroma $\left(\mathrm{C}^{*}\right)$ of unmordanted sample recorded higher than that of simultaneous, pre and post-mordanted samples. Whereas, in pashmina fabric Chroma $\left(\mathrm{C}^{*}\right)$ of simultaneous mordanted sample recorded higher followed by post, pre and lowest in unmordanted dyed sample. The mordanting methods showed variation in shades of both wool and pashmina fabrics (Fig 2). In wool fabric, hue angle $\left(\mathrm{h}^{\circ}\right)$ ranged from 74-82, indicating light reddish, brownish and yellowish shades of wool fabric. Whereas, hue angle $\left(\mathrm{h}^{\circ}\right)$ of pashmina fabric ranged from 76.00-80.50, indicating reddish yellow, brownish and yellowish shades. Highest total colour change $(\Delta \mathrm{E})$ was recorded in unmordanted wool sample followed by post, simultaneous and pre- mordanted samples. In pashmina fabric unmordanted sample recorded higher colour change $(\Delta \mathrm{E})$ followed by simultaneous, post and pre-mordanted samples. The mordant used has a greater influence on the colour strength $(\mathrm{K} / \mathrm{S})$. The colour strength and relative colour strength $(\mathrm{K} / \mathrm{S})$ of pashmina fabric recorded higher than that of wool fabric. In pashmina fabric highest colour strength $(\mathrm{K} /$ $\mathrm{S})$ was recorded in simultaneous mordanted sample followed by post and unmordanted sample, whereas pre mordanted dyed sample recorded lowest $\mathrm{K} / \mathrm{S}$ and relative $\mathrm{K} / \mathrm{S}$ value. The colour strength and relative colour strength $(\mathrm{K} / \mathrm{S})$ of wool fabric recorded highest in post mordanted sample followed by unmordanted sample, simultaneous and pre-mordanted samples (Table 1). The increase in the colour strength of the dyed fabric by using required quantity of the biomordant was supported by Guesmi et al. (2014), whereby they reported increase in colour strength of the dyed wool fabric by using bio-mordant and gradual increase of colour strength with increasing of bio-mordant concentration. The difference in colour strength of pashmina and wool fabrics adopting different mordanting 
Table 1. Colour coordinates of different fabrics treated with $Q$. robur (fruit cups) dye using S. alba (wood extract) as mordant.

\begin{tabular}{|c|c|c|c|c|c|c|c|c|}
\hline Methods CIE L*a*b* & $\mathbf{L}^{*}$ & $a^{*}$ & $\mathbf{b}^{*}$ & $C^{*}$ & $\mathbf{h}^{*}$ & $\Delta \mathbf{E}$ & $\mathbf{K} / \mathbf{S}$ & $\begin{array}{c}\text { Relative } \\
\mathbf{K} / \mathrm{S}\end{array}$ \\
\hline \multicolumn{9}{|c|}{ Wool fabric } \\
\hline Without mordant & 73.07 & 4.37 & 31.22 & 31.53 & 82.00 & 31.16 & 0.621 & 1.54 \\
\hline Pre-mordanting & 72.04 & 4.53 & 26.21 & 26.60 & 80.20 & 25.64 & 0.552 & 1.36 \\
\hline Simultaneous- mordanting & 64.66 & 6.07 & 28.36 & 29.00 & 77.90 & 27.72 & 0.574 & 1.42 \\
\hline Post-mordanting & 59.47 & 5.70 & 19.84 & 20.64 & 74.00 & 28.73 & 0.637 & 1.58 \\
\hline \multicolumn{9}{|c|}{ Pashmina fabric } \\
\hline Without mordant & 55.71 & 4.34 & 25.53 & 25.90 & 80.30 & 26.95 & 0.667 & 1.49 \\
\hline Pre-mordanting & 61.57 & 4.97 & 26.62 & 27.08 & 79.40 & 22.42 & 0.637 & 1.42 \\
\hline Simultaneous- mordanting & 57.34 & 6.87 & 27.65 & 28.49 & 76.00 & 26.72 & 0.711 & 1.59 \\
\hline Post-mordanting & 57.55 & 4.57 & 27.32 & 27.70 & 80.50 & 26.00 & 0.671 & 1.50 \\
\hline
\end{tabular}

methods may be due to formation of coordinate complex between dye and mordant and their aggregation inside the fibre leading to linear increase in colour strength of the dyed fabrics (Temani et al., 2011). The difference in the shade of dyed fabrics with different mordants and mordanting methods may be due to unique complex formation of bio- mordant and natural dye when applied by different methods on fabrics resulting in different shades of the dyed fabrics (Kampeerapappun et al., 2010). The change in colour of the dyed wool and pashmina fabrics with different mordants may be due to difference in coordination complexes formed between dye and mordant during different mordanting methods (Lal et al., 2011).

Colour fastness properties of dyed wool and pashmina fabrics: The fastness properties of selected dyed fabrics are presented in table 2 . The washing, light and rubbing fastness properties of both wool and pashmina fabrics were satisfactory. In washing fastness, grades of colour staining recorded higher than grades of colour change in majority of the combinations. Whereas, grades of rubbing fastness recorded higher in dry staining and fading than that of wet staining and fading. The grades of fastness properties showed slight differences where unmordanted samples of wool and pashmina fabrics also recorded satisfactory grades with higher grades of fastness in mordanted samples. The unmordanted dyed samples exhibited slight lower fastness properties and the majority of the mordanted samples showed an improved fastness properties. The method of mordanting showed significant differences in fastness properties of dyed pashmina and wool fabrics.

Washing fastness: In wool fabric, simultaneous mordanted sample recorded excellent (5) colour change grade followed by pre and post mordanted samples which recorded good to excellent to excellent (4/5) grades

Table 2. Fastness grades of wool and pashmina fabrics dyed with $Q$. robur (fruit cups) and $S$. alba (wood extract) adopting different mordanting methods.

\begin{tabular}{|c|c|c|c|c|c|c|c|}
\hline \multirow[t]{3}{*}{ Method } & \multirow{2}{*}{\multicolumn{2}{|c|}{$\begin{array}{l}\text { Washing } \\
\text { fastness }\end{array}$}} & \multirow{3}{*}{$\begin{array}{c}\text { Light } \\
\text { fastness }\end{array}$} & \multicolumn{4}{|c|}{ Rubbing fastness } \\
\hline & & & & \multicolumn{2}{|c|}{ Staining } & \multicolumn{2}{|c|}{ Fading } \\
\hline & $\mathbf{C C}$ & CS & & Dry & Wet & Dry & Wet \\
\hline \multicolumn{8}{|c|}{ Wool } \\
\hline Without mordant & 4 & $4 / 5$ & $4 / 5$ & $4 / 5$ & $4 / 5$ & 5 & $4 / 5$ \\
\hline Pre-mordanting & $4 / 5$ & 5 & $4 / 5$ & 5 & 5 & 5 & $4 / 5$ \\
\hline Simultaneous-mordanting & 5 & 5 & 5 & $4 / 5$ & 4 & 5 & $4 / 5$ \\
\hline Post-mordanting & $4 / 5$ & $4 / 5$ & $4 / 5$ & 5 & $4 / 5$ & 5 & 5 \\
\hline \multicolumn{8}{|c|}{ Pashmina } \\
\hline Without mordant & $4 / 5$ & 5 & $4 / 5$ & $4 / 5$ & 4 & 5 & 5 \\
\hline Pre-mordanting & 5 & 5 & $4 / 5$ & 5 & $4 / 5$ & 5 & $4 / 5$ \\
\hline Simultaneous-mordanting & 5 & 5 & $4 / 5$ & 5 & $4 / 5$ & 5 & 5 \\
\hline Post-mordanting & $4 / 5$ & 5 & $4 / 5$ & $4 / 5$ & $4 / 5$ & 5 & 5 \\
\hline
\end{tabular}

CC: Colour change; CS: Colour staining 


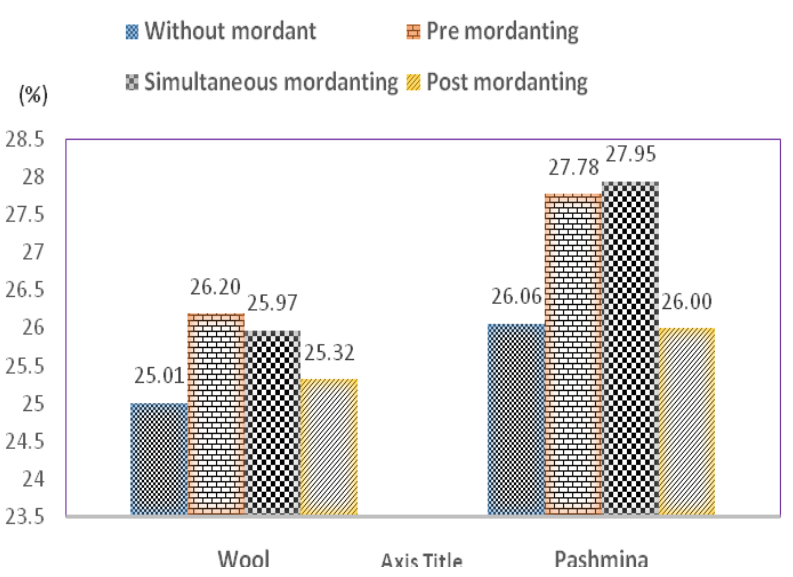

Fig. 1. Percent absorption of wool and pashmina fabrics.

and the without mordanted sample recorded good (4) grade. However, in pashmina fabric excellent (5) grade was recorded in pre and simultaneous mordanted samples whereas, unmordanted and post mordanted samples recorded same fastness grades (4/5). Colour staining of pre and simultaneous mordanted samples excellent (5) was recorded higher than that of unmordanted and post mordanted dyed samples which recorded (4/5) fastness grade. Colour staining of pashmina fabric recorded excellent (5) grades in all mordanting methods adopted including unmordanted sample.

Light fastness: Light fastness properties of both wool and pashmina fabrics does not showed much difference and recorded Good to excellent to excellent (4/5) grades in all mordanted samples except in simultaneous mordanted wool sample which recorded excellent (5) light fastness grade.

Rubbing fastness: Dry rubbing fastness of wool fabric recorded excellent (5) grade in pre and post mordanted samples. Whereas, unmordanted and simultaneous mordanted sample recorded same fastness grade of good to excellent to excellent (4/5). In wool fabric wet staining recorded excellent (5) grade in pre mordanted sample. Whereas, unmordanted and post mordanted samples recorded good to excellent to excellent $(4 / 5)$ grade and lowest grade was recorded in simultaneous mordanted sample which recorded good (4) grade. In pashmina fabric pre, simultaneous and post mordanted samples recorded same fastness grade of good to excellent to excellent (4/5) whereas, unmordanted sample recorded lowest grade of good (4). Dry fading of wool and pashmina fabric does not showed any change and recorded excellent (5) grade in all methods including without mordant samples. In wool fabric, wet staining of post mordanted dyed sample recorded excellent (5) grade and rest of the dyed samples showed good to excellent to excellent $(4 / 5)$ grade. Whereas, in pashmina fabric excellent (5) grade was recorded in unmordanted, simultaneous and post mordanted sample. However, pre mordanted sample recorded good to excellent to excellent $(4 / 5)$ grade (Table 2). This can be supported by the formation of mordant and dye complexes which are able to form coordination linkages between the dye and mordant resulting in higher fastness grades of the dyes and mordants when applied on the fabric (Ali, 2007). The washing fastness of the dye is influenced by the rate of the diffusion of the dye and state of the dye inside the fibre (Jothi, 2008). Good light fastness is due to the formation of complex with the mordant which protects chromatophore from photolytic degradation (Kulkarni et al., 2011). The higher grades of the wet rub fastness than dry rub fastness may be due to dissolving of water soluble dye molecules which make them easier to get removed from the fibre by rubbing (Haji, 2010).

\section{Conclusion}

The natural dye and bio mordant from the plant material have been used effectively for the dyeing of the selected fabrics. The extracted dye showed a variety of colour shades when used in combination with natural mordant adopting different mordanting methods. The natural mordant enhanced the colour strength and fastness properties of the selected fabrics. $Q$. robur (fruit cups) and $S$. alba (wood extract) has been used for the first time as a potential source of dyeing material, having an excellent dyeing potential for wool and pashmina fabrics. Thus, the natural dye and mordant can be suggested as a potential substitute to synthetic dyes which causes environmental pollution.
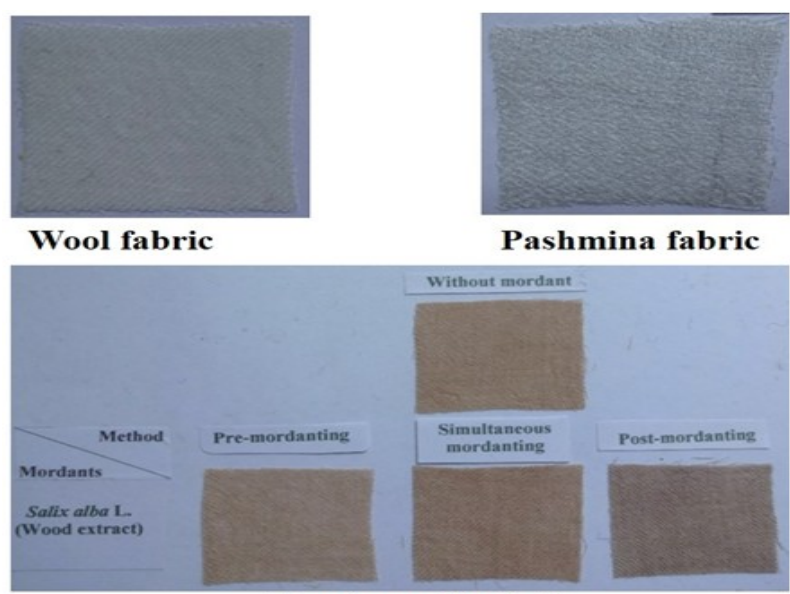

Dyed wool fabric

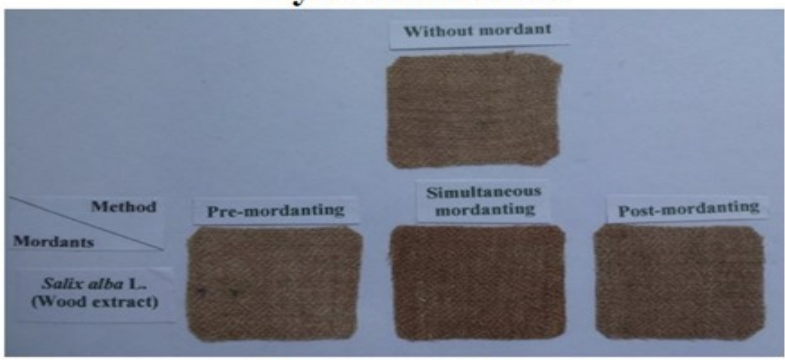

Dyed pashmina fabric

Fig 2. Wool and Pashmina fabrics dyed with different mordanting 


\section{ACKNOWLEDGEMENTS}

The author is highly thankful to Ministry of Minority Affairs and University Grants Commission for funding research work, Department of Chemical Engineering and Technology, IIT(BHU), Facility of Pashmina Quality Evaluation Laboratory developed by Division of LPT (SKUAST-K) and Division of Environmental Sciences (SKUAST-K) for providing support and laboratory facilities.

\section{REFERENCES}

Adeel, S., Ali, S., Bhartti, I.A. and Zsila, F. (2009). Dyeing of Cotton fabric using Pomegranate (Punica granatum) aqueous extract. Asian Journal of Chemistry. 21 (5) : 3493-3499.

Ali, S. (2007). Evaluation of cotton dyeing with aqueous extracts of Natural dyes from indigenous Plants. Ph.D Thesis. Department of chemistry. University of Agriculture, Faisalabad (Pakistan).

Aminoddin and Haji, A. (2010). Functional dyeing of Wool with natural dye extracted from Berberis vulgaris wood and Rumex hymenosepolus root as biomordant. Iran. J. Chem. Chem. Eng. 3 (29) : 55-60.

Atayde, C.M., Goncalez, J.C. and Camargos, J.A. (2011). Colorimetric characteristics of different anatomical sections of Muirapiranga (Brosimum sp.) wood. Cerne. 17 (2) : 231-235.

Arun, K.P. and Yogamoorthi, A. (2014). Isolation, application and biochemical characterization of colour component from Tecoma stans: A new cost effective and eco-friendly source of natural dye. International Journal of Natural Products Research. 4 (1) : 9-11.

Aung, T.T. and Win, N.Y. (2008). Extraction of Natural Mordant from Plant Source for Dyeing Application. GMSARN. International Conference on Sustainable Development: Issues and Prospects for the GMS, pp. 1-5.

Ben, M.H., Houas, I., Montassar, F., Ghedira, K., Barillier, D., Mosrati, R. and Chekir, G.L. (2012). Alteration of in vitro and acute in vivo toxicity of textile dyeing wastewater after chemical and biological remediation. Environmental science and pollution research international. DOI 10.1007/s11356-012-0802-7.

Divya, E., Madhumitha, T., Nandini, R., Pooja, R., Manickam, A.D. and Rekha, V.B. (2013). Extracation of natural dyes from forest trees and their application textiles. International Journal for Scientific Research and Development. $1(3): 561-565$.

Ferda, K., Adem, O. and Derya, S. (2010). Usage of Willow extract as mordant agent and dyeing of wooden and fiber samples with onion (Allium cepa) shell. RASAYAN Journal of Chemistry. 3 (1) : 1-8.

Goodarzian, H. and Ekrami, E. (2010). Extraction of dye from Madder plant (Rubia tictorium L.) and dyeing of wool. World Applied Sciences Journal. 9 (4): 434-436.

Guesmi, A.N., Ladhari, N., Hamadi, B., Msaddek, M. and Sakli, F. (2014). First application of chlorophyll-a as biomordant: sonicator dyeing of wool with betanin dye. Journal of cleaner production. 39 : 97-104.

Haji, A. (2010). Functional dyeing of wool with natural dye extracted from Berberis vulgaris wood and Rumex hymenosepolus root as Biomordant. Iran. J. Chem. Chem. Eng. 29 (3) : 55-59.

Jothi, D. (2008). Extraction of natural dyes from African Marigold flower (Tagetes erectal) for textile coloration. AUTEX Journal. 8 (2) : 49-53.

Kampeerapappun, P., Phattararittigul, T., Jittrong, S. and Kullachod, D. (2010). Effect of Chitosan and mordants ion dyeability of cotton fabrics with Ruellia tuberosa Linn. Chiang Mai J. 38 (1): 95-104.

Kulkarni, S.S., Bodake, U.M. and Pathode, G.R. (2011). Extraction of natural dye from Chili (Capsicum annum) for textile coloration. Universal Journal of Environmental Research and Technology. $1: 58-63$.

Kumar, V and Bharti, B.V. (1998). Eucalyptus yields dye. The Indian Textile Journal. 10 : 18-20.

Lal, C., Raja, A.S.M., Pareek, P.K., Shakyawar, D.B., Sharma, K.K. and Sharma, M.C. (2011). Juglans nigra: Chemical constitution and its application on Pashmina (Cashmere) fabric as a dye. Journal Natural of Products and Plant Resources. 1 (4) : 13-19.

Padmavathy, S., Sandhya, S., Swaminathan, K., Subrahmanyam, Y.V., Chakrabarti, T. and Kaul, S.N. (2003). Aerobic decolourization of Reactive Azo dyes in presence of various co substrates. Chem. Biochem. Eng. Q. 17 (2) : $147-151$.

Patel, A.R. (2011). Pink shade developed on Cotton yarn from Rubia cordifolia Linn. Life Sciences Leaflets. 19 : 780-784.

Prabhu, K.H. and Bhute, A.S. (2012). Plant based natural dyes and mordants: A Review. J. Nat. Prod. Plant Resour. 2 (6): 649-664.

Prado, A.G.S., Torres, J.D., Faria, E.A. and Dias, S.C.L. (2004). Comparative adsorption studies of indigo carmine dye on chitin and chitosan. Journal of Colloid and Interface Science. 1 (1) : 43-47.

Temani, P., Shakyawar, D.B., Ammayappan, L., Goyal, V. and Wani, S.A. (2011). Standardization of dyeing condition of Cochineal extract on Pashmina yarn. Journal of the Textile Association. 72 (2) : 90-92

Tiwari, H.C., Singh, P., Mishra, P.K. and Srivastava, P. (2010). Evaluation of various techniques for extraction of natural colorants from pomegranate rind - Ultrasound and enzyme assisted extraction. Indian Journal of Fibre and Textile Research. $35: 272-276$.

Vankar, P.S. (2000). The Chemistry of Natural dyes. General Article. Resonance, pp. 73-80.

Vankar, P.S. and Rakhi, S. (2008). Ecofriendly ultrasonic natural dyeing of cotton fabric with enzyme pretreatments. Desalination. 230 (1/3) : 62-69.

Wilkinson, S.M. and Mcgechaen, K. (1996). Occupational Allergic contact Dermatitis from Reactive dyes. Contact Dermatitis. 35 (6) : 376-378. 